\title{
Double-chambered Left Ventricle: Clinical Features Comparison between Children and Adults
}

\author{
Shi-Min Yuan \\ Department of Cardiothoracic Surgery, The First Hospital of Putian, Teaching Hospital, Fujian Medical University, Putian 351100,
} Fujian Province, China

\begin{abstract}
Double-chambered left ventricle is a rare congenital heart defect. The clinical features, diagnosis, treatment and patient prognosis of this lesion have not been sufficiently elaborated. The present systematic review found that the accessory ventricular septum was often an abnormal muscle band, and sometimes a membranous structure, a fibromuscular ridge, or prominent trabeculations. Less than one-third of the patients are associated with other congenital heart defects. Diagnosis of double-chambered left ventricle can usually be made by transthoracic echocardiography; however, it might be misdiagnosed as atrial or ventricular septal defect. The accessory chamber was often smaller than the main chamber, and often has wall thinning. The accessory chamber wall dysfunction/hypokinesis was seen in half of the cases. One-third patients had left ventricular outflow tract obstruction. The adult patients showed abnormal electrocardiographic findings more than in pediatrics. Nevertheless, no differences were found between adult and pediatric patients in terms of left ventricular function and structure, treatment of choice, and patient outcomes. Most patients are asymptomatic with no left ventricular obstruction, and thus do not need surgical treatment. Surgical resection of the accessory ventricular septum is warranted when the patients become symptomatic as a result of left ventricular obstruction, or associated with other congenital heart defects. The patients' outcomes are promising. Differential diagnosis should be made from other types of left ventricular outpouching, other congenital heart defects, and left ventricular non-compaction.
\end{abstract}

Key Words: Diagnosis, Differential, Heart defects, Congenital, Ventricular outflow obstruction.

How to cite this article: Shi-Min Yuan. Double-chambered left ventricle: Clinical features comparison between children and adults. $J$ Coll Physicians Surg Pak 2019; 29(11):1087-91.

\section{INTRODUCTION}

Double-chambered left ventricle (DCLV) is a rare condition in which the left ventricular cavity is divided into two parts by an abnormal accessaory ventricular septum. ${ }^{1}$ Due to its rarity, it may be misdiagnosed as simple congenital heart defects, ${ }^{2}$ or confused with double-chambered right ventricle, ${ }^{3}$ or with other types of left ventricluar outpouching. ${ }^{4}$ Thus, this congenital heart defect has shown important clinical implications. Moreover, the clinical features of DCLV have not been sufficiently described. In order to give an overview of this rare lesion, a comprehensive review is made.

\section{METHODOLOGY}

The preferred reporting items for systematic reviews and meta-analyses (PRISMA) statement guidelines were followed in this meta-analysis. Publications were systematically searched in the PubMed, Highwire Press, and the Cochrane Library databases from January 2000

Correspondence to: Shi-Min Yuan, Department of Cardiothoracic Surgery, The First Hospital of Putian, Teaching Hospital, Fujian Medical University, Putian 351100, Fujian

Province, China

E-mail: shiminyuan@126.com

Received: January 31, 2019; Revised: April 11, 2019;

Accepted: April 11, 2019 to December 2018. The MeSH terms and keywords used to identify articles included double-chambered, two-chambered, left ventricle, double-chambered left ventricle, anomalous muscle bundles, and accessory ventricular septum. The screening of the bibliographic references helped in completing the literature retrieval. Thirty-three articles related to the topic were found and keywords in the literature search; and 29 articles, which met the inclusion and exclusion criteria during preliminary assessment, were included in the review. The exclusion criteria were articles of: double-chambered right ventricle $(n=2)$, patient was misdiagnosed as DCLV $(n=1)$, and other types of left ventricular outpouching $(n=1)$.

The data independently extracted from each study were the study population, demographics, clinical manifestations, diagnostic techniques, intra-left ventricular pressure gradients, associated disorders, nature of the accessory ventricular septum, treatment of choice, and patient outcomes.

SPSS software version 22.0 was used for statistical analysis. The measurement data were expressed in mean \pm standard deviation and were compared by independent sample/paired t-test. The categorical variables were compared by Fisher exact test. $p<0.05$ was considered statistically significant. 


\section{RESULTS}

The 29 case reports, which dealt with a single patient in each, included in total 29 patients. 1,2,5-31 One case was a 24-week gestation fetus, whose gender was not reported. 29 For the remaining 28 patients, $20(71.4 \%)$ were males and $8(28.6 \%)$ were females with a male-tofemale ratio of $2.5: 1$. Their mean age was $28.6 \pm 11.7$ years $(n=28)$. There was no age difference between the male and the female patients $(28.2 \pm 18.0$ years $v s$. 25.4 $\pm 17.0, \mathrm{p}=0.758$ ).

There were $10(34.5 \%)$ pediatric patients (including the fetal case), $2,6,11,13,16,17,19,28-30$ and $19(65.5 \%)$ adult patients $\left(\chi^{2}=5.59, p=0.035\right) .1,5,7-10,12,14,15,18,20-27,31$

Fourteen patients (48.3\%) were asymptomatic, $2,6,8,13,14,16$, $17,22-24,26,27,29,31$ while $15(51.7 \%)$ were symptomatic $\left(\chi^{2}=0.00, p=1.000\right) .1,5,7,9-12,15,18-21,25,28,30$

Among 14 asymptomatic patients, 6 (42.9\%) were pediatrics (including the fetal case), and 8 (57.1\%) were adults $\left(\chi^{2}=0.57, p=0.706\right)$. There were 31 clinical presentations in 15 symptomatic patients, where the most common symptoms were chest pain and palpitation. Their duration of symptoms was $22.5 \pm 25.1$ months $(n=5)$. Heart murmur was described in 13 $(13 / 29,44.8 \%)$ patients: in $4(4 / 13,30.8 \%)$ patients, no heart murmur was audible, $2,18,25,31$ and in $9(69.2 \%)$ patients, a systolic murmur was heard $\left(\chi^{2}=3.85\right.$, $\mathrm{p}=0.115) \cdot 1,5,6,11,12,21,28,30$

The locations of the murmurs were: left sternal border $(n=4), 1,11,12,30$ apex $(n=2), 21,28$ base $(n=1), 5$ mesocardiac area $(n=1),{ }^{6}$ and unspecified $(n=1) .23$

In 20 pateints, their electrocardiographic (ECG) findings were available: the ECG findings were normal in $6(30 \%)$ patients. $2,6,25,26,29,31$ In comparison, an abnormal ECG was seen in the remaining $14(70 \%)$ patients $\left(\chi^{2}=6.40\right.$, $\mathrm{p}=0.026)$. In the 6 patients with a normal ECG, $3(50 \%)$ were pediatric and $3(50 \%)$ were adult cases $\left(\chi^{2}=0.00\right.$, $p=1.000)$; while $3(21.4 \%)$ patients with an abormal ECG finding were pediatrics and $11(78.6 \%)$ were adults $\left(\chi^{2}=9.14, p=0.007\right)$. The abnormal electrocardiographic findings were heterogeneous, such as left bundle branch block, ${ }^{15,18}$ atrial fibrillation, ${ }^{20}$ and left anterior hemiblock, ${ }^{9}$ etc.

All patients were initially inspected by transthoracic echocardiography, by which signs of DCLV could be visible as, a finger-like projection muscle band,23 pronounced trabeculations interspersed by deep recesses, 22 flows in the intertrabecular recesses, 8 thinning of the left ventricular wall and the interventricular septum, 10 and aneurysm-like structure. 15 But in 2 patients, the DCLV was primarily diagnosed as ventricular septal defect, 24 and ventricular and atrial septal defects, 2 respectively.

Nine $(9 / 29,31.0 \%)$ patients have one or more congnital heart defects, and $19(19 / 29,65.5 \%)$ pateints were associated with other cardiac abnormalities (Table I).
Table I: The associated congenital heart defects and secondary cardiac anomalies.

Congenital heart defect

1. VSD (perimembrane+muscular), Eisenmenger symdrome, TR, mitral valve prolapse, MR, DCRV $(n=1)^{5}$

2. VSD (multiple, muscular, swiss-cheese), ASD, left circumflex artery with an anormal origin from the proximal RCA $(n=1)^{7}$

3. VSD (multiple, muscular, swiss-cheese) $(n=1)^{17}$

4. Subaortic obstruction (tunnel-type), mitral valve prolapse $(n=1)^{10}$

5. Partial atrioventricular canal $(n=1)^{23}$

6. Subaortic obstruction $(n=1)^{11}$

7. Aortic stenosis $(n=1)^{19}$

8. $\operatorname{ASD}(n=1)^{30}$

9. LV non-compaction $(n=1)^{8}$

Secondary cardiac anomalies

1. LVOTO $(n=11)$

2. Myocardial scarring/fibrosis $(n=4)$

3. Coronary lesion $(n=10)$

4. Hypertension $(n=8)$

5. Pulmonary artery hypertension $(n=3)$

6. Diffuse subendocardial fibrosis $(n=1)^{10}$

7. Cardiac necrosis markers $(+)(n=1)^{25}$

8. Coronary embolism with subsequent ST-segment elevation myocardial infarction and transient ischemic attack $(n=1)^{9}$

9. IVS hypertrophy $(n=1)^{26}$

10. LV hypertrophy, RV contractile aneurysm, MR, TR $(n=1)^{12}$

11. Apical $R V$ aneurysm, right atrial dilation, $R V$ hypertension $(n=1)^{11}$

ASD: atrial septal defect; DCRV: double-chambered right ventricle; IVS: interventricular septum; LV: left ventricle; LVOTO: left ventricular outflow tract obstruction; MR: mitral regurgitation; RCA: right coronary artery; RV: right ventricle; TR: tricuspid regurgitation; VSD: ventricular septal defect.

Table II: The nature of the accessory septum of the left ventricle.

\begin{tabular}{|c|c|}
\hline Accessory septum & $n(\%)$ \\
\hline A muscle band $2,6,7,8,10,15,16,20,22,23,26$ & $11(55)$ \\
\hline A membranous structure $e^{1,13,19,27}$ & $4(20)$ \\
\hline A fibromuscular ridge $11,21,28$ & $3(15)$ \\
\hline Prominent trabeculations ${ }^{9,14}$ & $2(10)$ \\
\hline
\end{tabular}

Besides, 2 (2/29, 6.9\%) patients had genetic problems: MYH7 rare variant, ${ }^{28}$ and Vacterl association. ${ }^{2}$

The dimensions of the accessory chamber of the left ventricle was (described as long axis $\times$ short axis, $\mathrm{mm}^{2}$ ) measured as $1898,271392,251020,182000,{ }^{14}$ and 378,30 with a mean of $1337.6 \pm 666.6 \mathrm{~mm}^{2}$. A comparison between those of the adult, 14,18,25,27 and that of the pediatric patients, 30 showed a significant difference (1577.5 $\pm 228.5 \mathrm{~mm}^{2}$ vs. $378 \mathrm{~mm}^{2}, \mathrm{p}=0.011$ ). An adult patient was reported to have an end diastolic volume of the accessory left ventricle of $38 \mathrm{~mL} / \mathrm{m}^{2} .22$ The size of intra-left ventricular communication was $1.2 \pm 0.8 \mathrm{~cm}$ $(n=7)$. Flow velocity across the accessory ventricular septum was $1.1 \pm 0.3 \mathrm{~m} / \mathrm{s}$ during systole, $1,29,31$ and was $1.0 \pm 0.3 \mathrm{~m} / \mathrm{s}$ during diastole. ${ }^{29,31}$ The intra-left ventricle pressure gradient before treatment was reported for 8 patients: it was zero in five patients, $2,6,12,13,28$ (it rose to $55 \mathrm{mmHg}$ after exercise in one of them ${ }^{12}$ ). Their mean pressure gradient was $30.1 \pm 46.2 \mathrm{mmHg}(\mathrm{n}=8)$.

The pressure gradient decreased to $14.3 \pm 16.9 \mathrm{mmHg}$ $(n=3)$ after treatment.11,19,21 The post-treament pressure 
Table III: A comparison between left ventricular aneurysm and diverticulum.

\begin{tabular}{l|l|l|l}
\hline Feature & Aneurysm & Diverticulum & DCLV \\
\hline Communicating opening 4,15 & Wide neck & Narrow neck & By the anomalous septum or muscle bundle \\
Wall motion 4,15 & Dyskinetic & Absence of dyskinetic motion & Normal or dyskinetic \\
Wall structure 4,15 & Lack of full layers & Full layers & Full layers \\
Abnormal muscular and/or fiber bundles to division29 & No & No & Yes \\
Associated congenital mid-line defects22 & Seldom & Often & Seldom \\
\hline
\end{tabular}

DCLV: Double-chambered left ventricle.

gradient was much lower than that of before treatment, but lack of a statistical significance $(30.1 \pm 46.2 \mathrm{mmHg}$ vs. $14.3 \pm 16.9 \mathrm{mmHg}, \mathrm{p}=0.588$ ).

The nature of the accessory septum of the left ventricle was described for 20 patients, most of which were an abnormal muscle band (Table II). The accessory septum could be a complete, 19 or an incomplete structure.20,28 Their course was horizontal in several cases,1,19 and was Y-shaped in a patient. ${ }^{16}$

Other diagnostic techniques to confirm the diagnosis of DCLV included magnetic resonance imaging $(n=19)$, catheterisation/coronary angiography $(n=8), 3-D$ echocardiography $(n=3)$, and contrast echocardiography $(n=1)$.

One patient died of accident before diagnosis of DCLV was made. ${ }^{14}$ Besides, mangement of 14 (14/29, 48.3\%) patients was mentioned: $11(78.6 \%)$ were conservatively and $3(21.4 \%)$ were surgically treated $\left(\chi^{2}=9.14, p=0.007\right)$.

The surgical indications of the 3 pateints undergoing a surgical treatment were an intra-left ventricular pressure gradient of $110 \mathrm{mmHg},{ }^{11}$ a high flow velocity of $>2 \mathrm{~m} / \mathrm{s},{ }^{1}$ and severe left ventricular outflow obstruction with necessity of concurrent Ross procedure. ${ }^{19}$ The conservative treatment of choice was based on that patient were asymptomatic and without left ventricular outflow obstruction.

The outcomes of $7(50 \%)$ patients were reported: 6 $(85.7 \%)$ were recovered and $1(14.3 \%)$ was improved. There were no differences between conservative and surgical treatments $\left(\chi^{2}=0.29, p=1.000\right)$ and between pediatric and adult patients $\left(\chi^{2}=0.19, p=1.000\right)$ in terms of pateints' outcomes (namely, event-free survival).

\section{DISCUSSION}

DCLV is a very rare congenital heart defect, and it is characterised by a division of the ventricular cavity by an anomalous septum of DCLV or muscle bundle.17 The accessory chamber of the left ventricle may have a thinned ventricular wall and hypokinesis. The impaired wall contractility serves to distinguish the DCLV from left ventricular aneurysm.

The embryology of DCLV remains uncertain. But it was proposed that DCLV might be the result of incomplete regression of the trabeculations, probably a variant of left ventricular non-compaction. ${ }^{15,32}$

Differential diagnosis of DCLV includes diverticulum and aneurysm of the left ventricle. Both ventricular aneurysm and ventricular diverticulum do not have the abnormal muscular and (or) fiber bundles for left ventricular division. ${ }^{29}$ In left ventricular aneurysm, as a result of myocardial infarction, the aneurysmal wall shows delayed gadolinium enhancement with impaired wall motion, either akinetic or dyskinetic. Left ventricular diverticulum contains all three layers of the myocardial tissues, and the connection to the left ventricular cavity is narrow. DCLV is also composed of all three layers of the myocardial tissues but there is a muscular or membranous accessory septum to separate the ventricle. The differential diagnoses between the three forms of left ventricular outpouching are of clinical importance as for the different management policies and patient outcomes (Table III). Left ventricular aneurysm and diverticulum may sometimes lead to systemic embolisation, cardiac dysfunction, valve insufficiency, myocardial rupture, severe ventricular arrhythmias, and even cardiac death. ${ }^{32}$ Moreover, the diagnosis of left ventricular noncompaction in which a giant trabecula, parallel to the interventricular septum, subdivided the left ventricle, thus simulating an accessory ventricular chamber. ${ }^{32}$

DCLV is usually asymptomatic and has a benign prognosis. Nevertheless, one case with coronary embolism and two cases with non-sustained ventricular tachycardia-ventricular fibrillation have been described. 15 When symptomatic or when associated with other cardiac abnormalities, surgical treatment is recommended. 33

The present study revealed that the accessory ventricular septum was often an abnormal muscle band, and sometimes a membranous structure, a fibromuscular ridge, or prominent trabeculations. Less than one-third of the patients are associated with other congenital heart defects. Diagnosis of DCLV can usually be made by transthoracic echocardiography; however, it might be misdiagnosed as atrial or ventricular septal defect. The accessory chamber was often smaller than main chamber, and often has wall thinning. The accessory chamber wall dysfunction/hypokinesis was seen in half of the case. One-third patients had left ventricular outflow tract obstruction. The adult patients showed abnormal ECG findings more than in pediatrics. Nevertheless, no differences were found between adult and pediatric patients in terms of left ventricular function and structure, treatment of choice, and patient outcomes.

\section{CONCLUSION}

DCLV is a rare congenital heart defect. Most patients are asymptomatic with no left ventricular obstruction, and 
thus do not need surgical treatment. Surgical resection of the accessory ventricular septum is warranted when the patients become symptomatic as a result of left ventricular obstruction, or associated with other congenital heart defects. The patients' outcomes are promising. Differential diagnosis should be made from other types of left ventricular outpouching, other congenital heart defects, and left ventricular non-compaction.

\section{CONFLICT OF INTEREST:}

Author declared no conflict of interest.

\section{AUTHOR'S CONTRIBUTION:}

SMY: Substantial contribution to the conception and design of the work; and the acquisition, analysis, and interpretation of data for the work; drafting the work and revising it critically for important intellectual content; final approval of the version to be published; agreement to be accountable for all aspects of the work in ensuring that questions related to the accuracy and integrity of any part of the work are appropriately investigated and resolved.

\section{REFERENCES}

1. Rajiah P, Thomas J, Smedira N, Desai MY. Double-chambered left ventricle due to fibroelastotic membrane: An unusual case. J Thorac Imaging 2012; 27:W5-7.

2. Al-Farqani A, Panduranga $\mathrm{P}$, Al-Maskari $\mathrm{S}$, Thomas $\mathrm{E}$. VACTERL association with double-chambered left ventricle: $A$ rare occurrence. Ann Pediatr Cardiol 2013; 6:200-1.

3. Baritakis N, Grapsas N, Kotsalos A, Davlouros P. An uncommon variant of double-chambered right ventricle masquerading as double-chambered left ventricle. Interact Cardiovasc Thorac Surg 2018; 26:350-2.

4. Awad SM, Patel AS, Polimenakos A, Braun R, Abdulla RI. Left ventricular accessory chamber: A case report and review of the literature. Pediatr Cardiol 2009; 30:1022-5.

5. Akdemir R, Balci MM, Ozer C, Karcaaltincaba M, Acikel S. Quadrichambered ventricles. Cardiol J 2010; 17:303-5.

6 Bilici M, Demir F, Akin A, Güzel A, Akdeniz O, Tan I. Echocardiographic diagnosis of double-chambered left ventricle. J Echocardiogr 2016; 14:176-8.

7. Breithardt OA, Ropers D, Seeliger T, Schmid A, von Erffa J, Garlichs C, et al. A heart within the heart: Double-chambered left ventricle. Eur J Echocardiogr 2008; 9:739-41.

8. Correia AS, Madureira AJ, Gonçalves A, Almeida PB, Araújo V. Double-chambered left ventricle plus left ventricular noncompaction: Report of an abnormal association. Eur Heart $J$ Cardiovasc Imaging 2013; 14:127.

9. Dallaglio PD, Claver E, Di Marco A, Alió J, Hidalgo A, Cequier A. Double-chambered left ventricle: Coronary embolism as the first presentation of an extremely unusual cardiac anomaly. J Cardiovasc Med (Hagerstown) 2017; 18:790-2.

10. Destounis A, Tountas C, Theodosis-Georgilas A, Zahos P, Kasinos N, Palios J, et al. An unusual case of doublechambered left ventricle. J Echocardiogr 2018.

11. Dogan OF, Alehan D, Duman U. Successful surgical manage- ment of a double-chambered left ventricle in a 13-year-old girl: A report of a rare case. Heart Surg Forum 2004; 7:E198-200.

12. Finocchiaro G, Murphy D, Pavlovic A, Haddad F, Shiran H, Sinagra $G$, et al. Unexplained double-chambered left ventricle associated with contracting right ventricular aneurysm and right atrial enlargement. Echocardiography 2014; 31:E80-4.

13. Ghosh GC, Alex AG, George PV. 'Chamber within a chamber': A rare cardiac anomaly. Cardiol Young 2017; 27:1423-5.

14. Gilbert JD, Byard RW. Double-chambered left ventricle A "heart within a heart". Forensic Sci Med Pathol 2018; 14:545-7.

15. Gufler H, Anderson RH, Annette M, Voigtlaender T. Doublechambered left ventricle in a patient with chest pain. Clin Res Cardiol 2018; 107:1180-2.

16. Harada K, Mori K, Ichimiya C, Terada N, lima T, Harada T, et al. Five-year follow-up two-dimensional speckle tracking echocardiography in a juvenile with a double-chambered left ventricle. Echocardiography 2017; 34:791-3.

17. Harikrishnan S, Sivasankaran S, Tharakan J. Double chambered left ventricle. Int J Cardiol 2002; 82:59-61.

18. Hemmers T, Schwaiger M, Stern H. Double chambered left ventricle in cardiac magnetic resonance imaging. Heart 2006; 92:1401.

19. Kaski JP, Kilner PJ, El-Saiedi S, van Doorn C, Yacoub M, Magee A. A new variety of double-chambered left ventricle. Eur Heart J 2010; 31:2676.

20. Kato M, Sasaki S, Dote K. Double-chambered left ventricle with ventricular fibrillation. Intern Med 2012; 51:2245-6.

21. Köz C, Yokusoglu M, Uzun M, Baysan O, Bulakbasi N. Doublechambered left ventricle with nonsustained ventricular tachycardia. Anadolu Kardiyol Derg 2009; 9:E5.

22. Masci PG, Pucci A, Fontanive P, Coceani M, Marraccini $P$, Lombardi M. Double-chambered left ventricle in an asymptomatic adult patient. Eur Heart J Cardiovasc Imaging 2012; 13:E1-3.

23. Masia SL, Sanna GD, Matta G, Balata A, Padua G. Doublechambered left ventricle and partial atrioventricular canal. Eur Heart J Cardiovasc Imaging 2015; 16:344.

24. Mordi I, Carrick D, Tzemos N. Diagnosis of double-chambered left ventricle using advanced cardiovascular imaging. Echocardiography 2013; 30:E206-8.

25. Nacif MS, Mello RA, Lacerda Junior OO, Sibley CT, Machado RA, Marchiori E. Double-chambered left ventricle in an adult: Diagnosis by CMRI. Clinics (Sao Paulo) 2010; 65:1393-5.

26. Nikolaidou C, Bazmpani MA, Tziatzios I, Toumpourleka M, Karvounis C, Karamitsos TD. Double-chambered left ventricle characterized by CMR. Hellenic J Cardiol 2017; 58:459-60.

27. Sanz J, Rius T, Kuschnir P, Macaluso F, Fuster V, Poon M. Double-chambered left ventricle: Complete characterization by cardiac magnetic resonance and multidetector-row computed tomography. Circulation 2004; 110:e502-3.

28. Wang J, Zhang X, Wang X, Wang C, Wang F, Wang B. MYH7 rare variant in a family with double-chambered left ventricle. Circ Cardiovasc Genet 2017; 10:e001729.

29. Xue C, Zhao Y, Zhang Y, Gu X, Han J, Henein M, et al. Doublechambered left ventricle diagnosis by $2 \mathrm{D}$ and $3 \mathrm{D}$ echocardio- 
graphy: From fetus to birth. Echocardiography 2019; 36:196-8.

30. Zhang WM, Chang DQ, Huang JJ, Maimaitiaili A, Ermek T, Yisireyili $\mathrm{M}$, et al. Double-chambered left ventricle: A rare case in a child. Echocardiography 2019; 36:192-5.

31. Zhang XY, Cao TS, Yuan LJ. Double-chambered left ventricle in echocardiography. Echocardiography 2012; 29:E67-8.
32. Novo G, Dendramis G, Marrone G, Novo S, Thiene G. Left ventricular noncompaction presenting like a double-chambered left ventricle. J Cardiovasc Med (Hagerstown) 2015; 16: 522-4.

33. Ohlow MA. Congenital left ventricular aneurysms and diverticula: Definition, pathophysiology, clinical relevance and treatment. Cardiology 2006; 106:63-72.

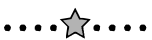

